Pacific Journal of Mathematic 


\title{
INTERSECTIONS OF NILPOTENT HALL SUBGROUPS
}

\author{
MARCEL HeRzoG
}

\begin{abstract}
A family $\mathscr{H}$ of subgroups of a finite group $G$ is said to satisfy (property) $B *$ if whenever $U=H_{1} \cap \cdots \cap H_{r}$ is a representation of $U$ as intersection of elements of $\mathscr{H}$ of minimal length $r$, then $r \leqq 2$. The aim of this paper is to prove
\end{abstract}

Theorem 1. Let $H$ be a nilpotent Hall $\pi$-subgroup of a group $G$ and assume that if $H_{1}, H_{2} \in S_{\pi}(G)$ then $H_{1} \cap H_{2} \triangleleft H_{1}$. Then $S_{\pi}(G)$ satisfies $B^{*}$.

All groups in this work are finite. A family $\mathscr{H}$ of subgroups of a group $G$ will be said to satisfy (property) $B$ if there exist $H_{1}$ and $H_{2}$ in $\mathscr{H}$ such that

$$
H_{1} \cap H_{2}=\bigcap\{H \mid H \in \mathscr{H}\} .
$$

We will denote by $S_{p}(G)$ the family of Sylow $p$-subgroups of $G$ and the (possibly empty) family of Hall $\pi$-subgroups of $G$ will be denoted by $S_{\pi}(G)$. It was shown by Brodkey [1] that if $G$ possesses an Abelian Sylow $p$-subgroup, then $S_{p}(G)$ satisfies $B$. Itô has shown in [3] that if $G$ is of odd order, hence solvable by [2], then $S_{p}(G)$ satisfies $B$ for all primes. He has also shown that if $G$ is solvable, then $S_{p}(G)$ satisfies $B$ in several other cases.

As indicated above, we will consider here a more restrictive condition $B^{*}$ on families of subgroups of $G$. It follows from our main result, Theorem 1, that even the property $B^{*}$ is satisfied by $S_{\pi}(G)$, whenever $G$ possesses an Abelian or Hamiltonian (i.e., Dedekind) Hall $\pi$-subgroup. Theorem 1 yields the following

Corollary 1. Let $H$ be a nilpotent Hall subgroup of the group $G$ and suppose that the index $\left[H: H \cap H^{x}\right]$ is prime for all $x \in G-N_{G}(H)$. Then either $H \triangleleft G$ or for all $x, y \in G$ such that $x y^{-1} \notin N_{G}(H)$ we have

$$
H^{x} \cap H^{y}=B \triangleleft G
$$

and $[H: B]=p$, a prime. $B$ is independent of $x$ and $y$.

2. Generalizations. As a matter of fact, we will prove a more general result than Theorem 1 . We will say that a group $N$ satisfies 
(property) $D_{\pi}$, where $\pi$ is a set of primes, if $N$ contains at least one Hall $\pi$-subgroup, any two Hall $\pi$-subgroups of $N$ are conjugate and each $\pi$-subgroup of $N$ is contained in a Hall $\pi$-subgroup of $N$. The set of all maximal $\pi$-subgroups of a group $G$ will be denoted by $\operatorname{Syl}_{\pi}(G)$. Theorem 1 follows from

THEOREM 2. Let the group $G$ satisfy the following conditions.

(i ) If $H_{1}, H_{2} \in \operatorname{Syl}_{\pi}(G)$ then $C=H_{1} \cap H_{2} \triangleleft H_{1}$ and

(ii) If $C=H_{1} \cap H_{2} \rtimes G$, then $N_{G}(C)$ satisfies $D_{\pi}$. Then $\operatorname{Syl}_{\pi}(G)$ satisfies $B^{*}$.

A subgroup $N$ of the group $G$ will be called $a \pi$-local subgroup of $G$ if $N=N_{G}(H)$, where $H$ is a nontrivial $\pi$-subgroup of $G$. An $N_{\pi}$-group is a group all of whose $\pi$-local subgroups are solvable. Theorem 1 yields the following

THEOREM 3. Let $G$ be an $N_{\pi}$-group and suppose that all its maximal $\pi$-subgroups are Dedekind groups. Then $\operatorname{Syl}_{\pi}(G)$ satisfies $B^{*}$.

As a consequence, we have

Corollary 2. Let $G$ be a nonsolvable $N_{\pi}$-group and suppose that each $H \in \operatorname{Syl}_{\pi}(G)$ is a Dedekind group. Then there exist $H_{1}, H_{2} \in \operatorname{Syl}_{\pi}(G)$ such that:

$$
o(G) \geqq o\left(H_{1}\right) o\left(H_{2}\right) \text {. }
$$

3. Proofs. We begin with a proof of Theorem 2. Let $U=$ $H_{1} \cap \cdots \cap H_{r}$ be a representation of $U$ as intersection of elements of $\operatorname{Syl}_{\pi}(G)$ of minimal length and suppose that $r>2$. It follows from assumption (i) and the minimality of $r$ that

$$
U \varsubsetneqq H_{1} \cap H_{2}=C \triangleleft H_{1}, H_{2} .
$$

The minimality of $r$ also implies that $C \not \subset H_{3}$ and consequently $C \not G$. By assumption (ii) $N=N_{G}(C)$ has the $D_{\pi}$-property and by (1) $H_{1}, H_{2} \in S_{\pi}(N)$. There exists $Q \in S_{\pi}(N)$ containing $H_{3} \cap \cdots \cap H_{r} \cap N$ and since the elements of $S_{\pi}(N)$ are conjugate in $N$, there exists $R \in S_{\tilde{r}}(N)$ such that $Q \cap R=C$. Since $Q$ and $R$ are conjugates of $H_{1}$, they belong to $\operatorname{Syl}_{\pi}(G)$. However,

$$
\begin{aligned}
U & =Q \cap R \cap H_{3} \cap \cdots \cap H_{r} \supset R \cap N \cap H_{3} \cap \cdots \cap H_{r} \\
& =R \cap H_{3} \cap \cdots \cap H_{r} \supset U
\end{aligned}
$$


in contradiction to the minimality of $r$. The proof of Theorem 2 is complete.

Theorem 1 follows immediately from Theorem 2 and Wielandt's Theorem [4] which states that if $G$ contains a nilpotent Hall $\pi$-subgroup then $G$ satisfies $D_{\bar{r}}$. Theorem 3 also follows immediately from Theorem 2.

Corollary 1 follows from Theorem 1. Suppose that $H \rtimes G$, and let $H_{1}, H_{2} \in S_{\pi}(G), H_{1} \neq H_{2}$. Since by our assumptions and the above mentioned Theorem of Wielandt $\left[H_{1}: H_{1} \cap H_{2}\right]$ is prime, it follows that $H_{1} \cap H_{2} \triangleleft H_{1}$. Let $B=\bigcap\left\{H^{x} \mid x \in G\right\}$; obviously $B \triangleleft G$ and since $H \bowtie G, B \varsubsetneqq H$. By Theorem 1 there exist $u, v \in G$ such that for all $x, y \in G$ we have:

$$
H^{u} \cap H^{v}=B \subset H^{x} \cap H^{y} .
$$

Suppose that $x y^{-1} \notin N_{G}(H)$; then $H^{x} \neq H^{y}$ and

$$
p=\left[H^{u}: B\right]=\left[H^{x}: B\right]=\left[H^{x}: H^{x} \cap H^{y}\right]\left[H^{x} \cap H^{y}: B\right] .
$$

Since $\left[H^{x}: H^{x} \cap H^{y}\right]>1$, it follows that $H^{x} \cap H^{y}=B$. The proof of Corollary 1 is complete.

Finally, Corollary 2 follows from Theorem 3. Since $G$ is a nonsolvable $N_{\pi}$-group, $\quad \bigcap\left\{H \mid H \in \operatorname{Syl}_{\tau}(G)\right\}=\{1\}$. Consequently, by Theorem 3, there exist $H_{1}, H_{2} \in \operatorname{Syl}_{\pi}(G)$ such that $H_{1} \cap H_{2}=\{1\}$. Obviously $o(G) \leqq o\left(H_{1}\right) o\left(H_{2}\right)$ and the proof is complete.

\section{REFERENCES}

1. J. S. Brodkey, A note on finite groups with an abelian Sylow group, Proc. Amer. Math. Soc. 14 (1963), 132-133.

2. W. Feit and J. G. Thompson, Solvability of groups of odd order, Pacific J. Math. 13 (1963), 755-1029.

3. N. Itô, Uber den kleinsten p-Durchshschnitt auflösbarer Gruppen, Arch. Math. 9 (1958), 27-32.

4. H. Wielandt, Zum Satz von Sylow, Math. Z. 60 (1954), 407-409.

Received June 3, 1970.

TEL-AVIV UNIVERSity

TEL-Aviv, IsRAeL 



\section{PACIFIC JOURNAL OF MATHEMATICS}

\section{EDITORS}

H. SAMELson

Stanford University

Stanford, California 94305

R. R. PHelPS

University of Washington

Seattle, Washington 98105
J. Dugundu

Department of Mathematics

University of Southern Californle

Los Angeles, California 9.0007

RICHARD ARENS

University of California

Los Angeles, California 9.0024

\section{ASSOCIATE EDITORS}
E. F. BECKENBACH
B. H. NeumanN
F. WOLE
K. Yoshida

\section{SUPPORTING INSTITUTIONS}

UNIVERSITY OF BRITISH COLUMBIA

CALIFORNIA INSTITUTE OF TECHNOLOGY

UNIVERSITY OF CALIFORNIA

MONTANA STATE UNIVERSITY

UNIVERSITY OF NEVADA

NEW MEXICO STATE UNIVERSITY

OREGON STATE UNIVERSITY

UNIVERSITY OF OREGON

OSAKA UNIVERSITY

UNIVERSITY OF SOUTHERN CALIFORNIA

\author{
STANFORD UNIVERSITY \\ UNIVERSITY OF TOKYO \\ UNIVERSITY OF UTAH \\ WASHINGTON STATE UNIVERSITY \\ UNIVERSITY OF WASHINGTON \\ AMERICAN MATHEMATICAL SOCIETY \\ CHEVRON RESEARCH CORPORATION \\ NAVAL WEAPONS CENTER
}

The Supporting Institutions listed above contribute to the cost of publication of this Journal, but they are not owners or publishers and have no responsibility for its content or policies.

Mathematical papers intended for publication in the Pacific Journal of Mathematics should be in typed form or offset-reproduced, (not dittoed), double spaced with large margins. Underline Greek letters in red, German in green, and script in blue. The first paragraph or two must be capable of being used separately as a synopsis of the entire paper. The editorial "we" must not be used in the synopsis, and items of the bibliography should not be cited there unless absolutely necessary, in which case they must be identified by author and Journal, rather than by item number. Manuscripts, in duplicate if possible, may be sent to any one of the four editors. Please classify according to the scheme of Math. Rev. Index to Vol. 39. All other communications to the editors should be addressed to the managing editor, Richard Arens, University of California, Los Angeles, California, 90024.

50 reprints are provided free for each article; additional copies may be obtained at cost in multiples of 50 .

The Pacific Journal of Mathematics is published monthly. Effective with Volume 16 the price per volume (3 numbers) is $\$ 8.00$; single issues, $\$ 3.00$. Special price for current issues to individual faculty members of supporting institutions and to individual members of the American Mathematical Society: $\$ 4.00$ per volume; single issues $\$ 1.50$. Back numbers are available.

Subscriptions, orders for back numbers, and changes of address should be sent to Pacific Journal of Mathematics, 103 Highland Boulevard, Berkeley, California, 94708.

PUBLISHED BY PACIFIC JOURNAL OF MATHEMATICS, A NON-PROFIT CORPORATION

Printed at Kokusai Bunken Insatsusha (International Academic Printing Co., Ltd.), 7-17, Fujimi 2-chome, Chiyoda-ku, Tokyo, Japan. 


\section{Pacific Journal of Mathematics}

\section{Vol. 36, No. 2 December, 1971}

George E. Andrews, On a partition problem of H. L. Alder ............ 279

Thomas Craig Brown, An interesting combinatorial method in the theory of locally finite semigroups .......................... 285

Yuen-Kwok Chan, A constructive proof of Sard's theorem ............. 291

Charles Vernon Coffman, Spectral theory of monotone Hammerstein

operators...................................... 303

Edward Dewey Davis, Regular sequences and minimal bases .......... 323

Israel (Yitzchak) Nathan Herstein and Lance W. Small, Regular elements in

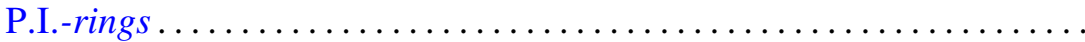

Marcel Herzog, Intersections of nilpotent Hall subgroups ..............

W. N. Hudson, Volterra transformations of the Wiener measure on the space

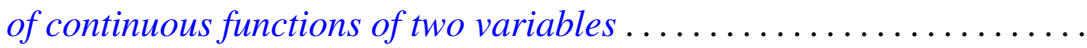

J. H. V. Hunt, An n-arc theorem for Peano spaces ................ 351

Arnold Joseph Insel, A decomposition theorem for topological group

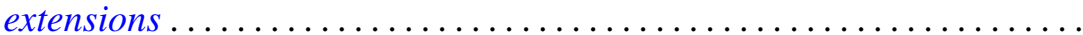

Caulton Lee Irwin, Inverting operators for singular boundary value

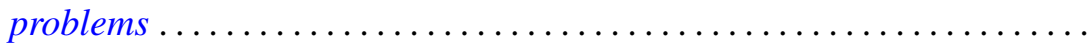

Abraham A. Klein, Matrix rings of finite degree of nilpotency ............ 387

Wei-Eihn Kuan, On the hyperplane section through a rational point of an algebraic variety...

John Hathway Lindsey, II, On a six-dimensional projective representation of $\mathrm{PSU}_{4}(3)$

Jorge Martinez, Approximation by archimedean lattice cones ...

J. F. McClendon, On stable fiber space obstructions .........

Mitsuru Nakai and Leo Sario, Behavior of Green lines at the Kuramochi boundary of a Riemann surface ....................

Donald Steven Passman, Linear identities in group rings. I. .

Donald Steven Passman, Linear identities in group rings. II ...

David S. Promislow, The Kakutani theorem for tensor products of

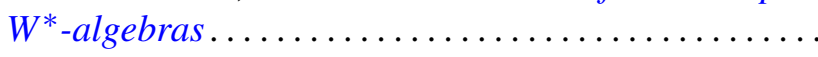

Richard Lewis Roth, On the conjugating representation of a finite group

Bert Alan Taylor, On weighted polynomial approximation of entire functions...

William Charles Waterhouse, Divisor classes in pseudo Galois

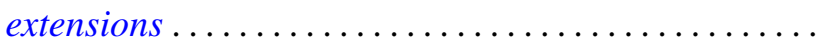

Chi Song Wong, Subadditive functions ...

Ta-Sun $\mathrm{Wu}$, A note on the minimality of certain bitransformation groups 